\title{
A Case Report: Life Saving Mallory-Weiss Syndrome
}

\author{
(D) Serkan Doğan, (D) Doğanay Can, (D) Büșra Bildik, (D) Utku Murat Kalafat, (D) Ahmet Erdur, (D) Ramiz Yazıcı, (D) Melis Dörter, \\ (D) Bașar Cander
}

Clinic of Emergency Medicine, University of Health Science, Kanuni Sultan Süleyman Training and Research Hospital, İstanbul, Turkey

\begin{abstract}
Mallory-Weiss syndrome is characterized by a mucosa rupture on the gastroesophageal junction and usually associated with intense retching, cough, straining, or vomiting. Methanol intoxication is a cause for severe mortality and morbidity. We aimed to emphasize the lifesaving importance of history taking, rapid diagnosis, and treatment for Mallory-Weiss syndrome secondary to methanol intoxication in the present case. A 54-year old male patient admitted to the emergency service by ambulance with the complaint of bloody vomiting. The patient's overall condition was moderate, and he was confused. He was taken into the resuscitation room. The patient was admitted to urgent endoscopy because of active bleeding. It was detected that he had drunk the alcohol that he made at home and presented bloody vomiting when he woke up in the morning. The patient was diagnosed with methanol intoxication and upper gastrointestinal system (GIS) bleeding. After intravenous infusion of $10 \mathrm{~mL} / \mathrm{kg}$ loading dose of $10 \%$ ethanol, infusion continued by $1.5 \mathrm{~mL} / \mathrm{kg} /$ hour. Urgent hemodialysis was implemented after infusion of $1 \mathrm{mEq} / \mathrm{kg} \mathrm{NaHCO}$ into the patient presenting severe acidosis. The patient was admitted for further tests and treatment after hemodialysis; he was discharged by cure after nine days. Mallory-Weiss syndrome may develop in GIS bleeding cases triggered by vomiting and have mortal causes. The complaints that start with severe vomiting may be caused by fatal conditions such as methanol intoxication like in the present case. Therefore, a detailed patient history, as well as rapid diagnosis and treatment by emergency clinicians, have vital importance.
\end{abstract}

Keywords: Mallory-Weiss syndrome, bleeding, methanol, intoxication, toxicology

\section{Introduction}

Mallory-Weiss syndrome, which is characterized by bleeding as a result of mucosa rupture on the gastroesophageal junction, is the cause of $1 \%$ to $4 \%$ of the cases with upper gastrointestinal system (GIS) bleeding. This syndrome is usually associated with intense retching, cough, straining, or vomiting (1). The syndrome was first identified by Kenneth Mallory and Soma Weiss in 1929 (2). This condition may be detected at any age; however, it is more common in the middle age and male gender by 2 to 4 folds (3). Excessive alcohol intake was detected in $40 \%$ to $80 \%$ of the patients diagnosed with Mallory-Weiss syndrome (4).

Methanol is a colorless and odorless alcohol type that is liquid at room temperature, and mortality and morbidity rates are higher in case of intoxication (5). The metabolites of methanol, formaldehyde, and formic acid are responsible for toxic side effects such as metabolic acidosis, blindness, hemodynamic instability, and death (6). The cases with methanol intoxication may refer to emergency service by complaints of the central nervous system (CNS) depression, visual disorders, abdominal pain, vomiting (7).

We aimed to emphasize the lifesaving importance of history taking, rapid diagnosis, and treatment for Mallory-Weiss syndrome secondary to methanol intoxication in the present case.

\section{Case Report}

A 54-year old male patient presenting bloody vomiting was taken to emergency service by ambulance. The patient's overall condition was moderate, and he was confused. He was taken 
into the resuscitation room. Blood pressure was 100/60 mmHg; pulse was $118 / \mathrm{min}$; respiration count was $20 / \mathrm{min} ; \mathrm{SpO}_{2}$ was $92 \%$. Physical examination was normal except tenderness in the epigastric region. The patient had no visual disorder before admitting to E.D. No bleeding was detected in rectal examination. Intravenous (IV) access was provided; $0.9 \%$ physiological saline, 80 mg pantoprazole, and antiemetic agent were infused; laboratory analysis was ordered simultaneously. Since the patient has active bleeding, he was taken to urgent endoscopy. Mucosa rupture was detected on the gastroesophageal junction by endoscopy, and endoscopic hemoclips were applied for treatment (Figure 1). Laboratory analysis revealed the following; blood gas $\mathrm{pH}=7.04$, $\mathrm{pO}_{2}=47.3 \mathrm{mmHg}, \mathrm{pCO}_{2}=23.3 \mathrm{mmHg}, \mathrm{HCO}_{3}=6.3 \mathrm{mEq} / \mathrm{dL}, \mathrm{BE}=-$ 22.6 anion gap $=24.8$. Biochemistry analysis was detected as follows: Urea $=42 \mathrm{mg} / \mathrm{dL}$, creatinine $=1.42 \mathrm{mg} / \mathrm{dL}$, white blood cell $=19.300 / \mathrm{mm}^{3}$, hemoglobin $=9.9 \mathrm{gr} / \mathrm{dL}$, platelet $=142.000$. Other laboratory parameters were normal. The patient's history revealed that he drank homemade alcohol at home the day before; and that he had nausea and vomiting the next morning, and then the bleeding started. The patient was diagnosed with methanol intoxication and upper GIS bleeding (Mallory-Weiss syndrome). Blood methanol levels could not be analyzed in our hospital. After IV infusion of $10 \mathrm{~mL} / \mathrm{kg}$ loading dose of $10 \%$ ethanol, infusion continued by $1.5 \mathrm{~mL} / \mathrm{kg} /$ hour. Urgent hemodialysis was implemented after infusion of $1 \mathrm{mEq} / \mathrm{kg} \mathrm{NaHCO}$ into the patient presenting severe acidosis. He was admitted for further tests and treatment after hemodialysis. The patient with no present bleeding and visual disorder was discharged in a cured state following three sessions of dialysis treatment.

\section{Discussion}

Methanol intoxication bears a higher risk of death due to the delay in referral and diagnosis (5). There may be a silent, symptom-free period for 40 minutes to 72 hours in the clinical presentation of methanol intoxication. At the end of the silent period, the patients may suffer headaches, blurry vision, nausea vomiting, and confusion (8). In the present case, the patient referred because of upper GIS bleeding as a result of severe retching and vomiting after 16 hours.

There is severe retching, cough, straining, or vomiting before bleeding in Mallory-Weiss syndrome (1). The present case also

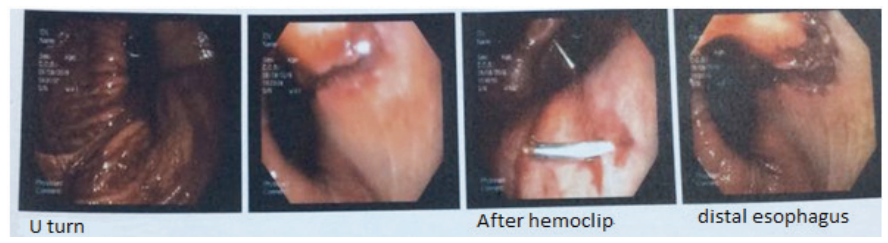

Figure 1. Urgent endoscopy image referred to severe retching and vomiting history before the bleeding in line with the literature. Excessive alcohol intake was detected in $40 \%$ to $80 \%$ of the patients diagnosed with MalloryWeiss syndrome (4). Our case also developed vomiting after alcohol intake.

The bleeding usually stops spontaneously in Mallory-Weiss syndrome, and the conservative approach is sufficient for most cases. When endoscopic findings demonstrate active bleeding, different endoscopic techniques (hemoclips, band-ligation, epinephrine injection) may be used (9). Since the active bleeding persisted in our case during endoscopy, hemoclips was performed for bleeding control as parallel to the literature.

Early diagnosis and treatment have vital importance in methanol intoxication. Patient history, visual disorder, and high anion gap metabolic acidosis are indicative of diagnosis (10). Blood methanol level provides the final diagnosis (11). However, analysis of the methanol level in the blood may not be performed in every laboratory; therefore, urgent treatment should be started in case of metabolic acidosis. Since we also could not detect the level of methanol in the blood, we repeated the history taking because of laboratory analyses indicating toxic alcohol intake as well as clinical suspicion. We started urgent treatment due to the diagnosis of methanol intoxication.

The general treatment approach for methanol intoxication includes gastric irrigation, ethanol infusion, hemodialysis, folate, and thiamine administration (6). Gastric irrigation is performed for the patients referring within the first hour; we did not implement gastric irrigation because our case referred 16 hours later. Oral, IV , or nasogastric administration of ethanol is used as an initial treatment for methanol intoxication. We performed IV ethanol treatment according to the literature. Fomepizole is a competitive inhibitor of alcohol dehydrogenase and prevents transformation into formic acid (12). We could not administer fomepizole, as this agent was not available in our hospital. If there are visual symptoms in methanol intoxication and CNS dysfunction findings as well as methanol level over $25 \mathrm{mg} / \mathrm{dL}$ and severe metabolic acidosis, dialysis should be performed (7). Hemodialysis was performed due to high anion gap metabolic acidosis.

\section{Conclusion}

Detailed patient history is vital for the patients presenting bloody vomiting to determine the precipitating cause of GIS bleeding. Mallory-Weiss syndrome may develop in upper GIS bleeding cases triggered by vomiting and have mortal causes. Therefore, a detailed patient history, as well as rapid diagnosis and treatment by emergency clinicians, have vital importance. 


\section{Ethics}

Informed Consent: Verbal informed consent was obtained from the patient who participated in this study.

Peer-review: Externally peer-reviewed.

\section{Authorship Contributions}

Surgical and Medical Practices: S.D., D.C, Concept: B.D., U.M.K., Design: A.E., M.D., Data Collection or Processing: R.Y., B.C., D.C., Analysis or Interpretation: S.D., U.M.K., B.C., Literature Search: D.C., B.B., M.D., Writing: U.M.K., D.C., S.D.

Conflict of Interest: No conflict of interest was declared by the authors.

Financial Disclosure: The authors declared that this study received no financial support.

\section{References}

1. Brown JD. Hiccups: An Unappreciated Cause of the Mallory-Weiss Syndrome. Am J Med. 2015;128:e19-20.

2. Jensen DM, Machicado GA, Hirabayashi K. Randomized controlled study of 3 different types of hemoclips for hemostasis of bleeding canine acute gastric ulcers. Gastrointest Endosc. 2006;64:768-73.

3. Sugawa C, Benishek D, Walt AJ. Mallory-Weiss syndrome. A study of 224 patients. Am J Surg. 1983;145:30-3.
4. Kortas DY, Haas LS, Simpson WG, NickI NJ 3rd, Gates LK Jr. Mallory-Weiss tear: predisposing factors and predictors of a complicated course. Am J Gastroenterol. 2001;96:2863-5.

5. Barceloux DG, Bond GR, Krenzelok EP, Cooper H, Vale JA; American Academy of Clinical Toxicology Ad Hoc Committee on the Treatment Guidelines for Methanol Poisoning. American Academy of Clinical Toxicology practice guidelines on the treatment of methanol poisoning. J Toxicol Clin Toxicol. 2002;40:415-46.

6. Berk WA, Henderson WV. Alcohols. In Tintinalli JE, Kelen GD. Stapczynski JS, editor. Emergency Medicine. A Comprehensive.Study Guide. 5th ed. New York: McGraw Hill; 2000. p.1103-9.

7. Kavalci C, Sezenler E, Kavalci G, Cevik Y, Turan M. Methanol poisoning: case report. JAEMCR. 2011;2:14-6

8. Keklikoglu HD, Yoldas TK, Coruh Y. Methanol Poisoning and Putaminal Hemorrhage: A Case Report. Journal of Neurological Sciences [Turkish]. 2007;24:338-42.

9. Bhattarai S, Dewan KR, Shrestha G, Patowary BS. Clinical and Endoscopic Profile of Patients with Mallory-Weiss Tears. Asian Journal of Medical Sciences. 2017;8:19-23.

10. Halavaara J, Valanne L, Setala K. Neuroimaging supports the clinical diagnosis of methanol poisoning. Neuroradiology. 2002;44:924-8.

11. Kurtoglu S. Toxications, Diagnosis and Treatment. Kayseri Erciyes University Publications. 1992.p. 209-32.

12. Megarbone B, Boron SW, Trout H, Hantson P, Jaeger A, Krencker E, et al. Treatment of acute methanol poisoning with fomepizole. Intensive Care Med. 2001;27:1370-8. 